\title{
Early pathogenesis of Listeria monocytogenes infection in the mouse spleen
}

\author{
J. W. CONLAN \\ Trudeau Institute Inc., PO Box 59, Saranac Lake, NY 12983, USA
}

\begin{abstract}
Histological observations suggested that in the spleen, blood-borne Listeria monocytogenes bacteria were preferentially ingested by two morphologically distinet mononuclear phagocyte populations present in the marginal zone of the white pulp. The morphologies of these phagocytes corresponded to those of marginal zone macrophages or marginal zone dendritic cells. Moreover, during the first day of infection, the same phagocytes containing listeria apparently translocated from the marginal zone into the white pulp where they established secondary infectious foci. This event was associated with a large influx of neutrophil polymorphonuclear leucocytes (PMNLs) into infected white pulp, and with the disappearance of lymphocytes from this compartment. White pulp lymphocytopenia also occurred in the spleens of listeria-infected mice selectively depleted of neutrophil PMNLs, indicating that these phagocytes were not responsible for displacing or destroying lymphocytes. The implications of these findings for explaining the virulence and immunogenicity of $L$. monocytogenes are discussed.
\end{abstract}

\section{Introduction}

Systemic murine listeriosis initiated by intravenous (i.v.) inoculation of Listeria monocytogenes has long served as a model for studying host defence against infections caused by intracellular bacterial pathogens in general [1]. In particular, studies with this model have contributed substantially to the concept that acquired T-cell-mediated immunity is an important component of host resistance to intracellular pathogens [2-7]. Additionally, studies with mice have revealed important aspects of $L$. monocytogenes virulence. For example, liver Kupffer cells remove up to $90 \%$ of an i.v. inoculum of $L$. monocytogenes and inactivate most ingested bacteria within the first few hours of infection [3]. Listeria that survive this host defence proceed to invade and proliferate inside hepatocytes to give rise to a progressive infection in the liver parenchyma $[8,9]$. The ability of $L$. monocytogenes to establish hepatic infection depends on its capacity to produce virulence factors [10] that allow it to multiply progressively at infectious foci in the liver in spite of the rapid and extensive accumulation of neutrophil polymorphonuclear leucocytes (PMNLs) at these sites [8]. Nevertheless, neutrophil-mediated defences severely restrict hepatic listeriosis to the extent that in mice specifically depleted of PMNLs, over 100 -fold more listeria than normal are recovered from the liver by $24 \mathrm{~h}$ of infection [9].

In contrast to Kupffer cells, resident splenic macrophages that remove the remaining $10-20 \%$ of an i.v.

Received 14 Aug. 1995; revised version accepted 4 Sept. 1995. inoculum of listeria [3] fail to inactivate the organisms they ingest. Furthermore, compared with the situation in the liver, PMNLs that accumulate at foci of listeria infection in the spleen only modestly restrict bacterial proliferation in this organ during the first day [9]. Thus, the spleen appears to be more susceptible than the liver to infection by $L$. monocytogenes. Indeed, splenectomised mice reportedly are more resistant to this infection than control mice [11]. On the other hand, the spleen is necessary for the generation of effective anti-listeria immunity in that splenectomised mice fail to develop specific acquired immunity to reinfection [11]. Presumably, the spleen provides the necessary micro-environment for antigen-presenting cells to induct antigen-specific $\mathrm{T}$ cells into the immune response [12]. Listeria-specific $\mathrm{CD}^{+}$and $\mathrm{CD}^{+} \mathrm{T}$ cells are generated in the spleen as early as day 2 of primary listeriosis [6], indicating that antigens derived from $L$. monocytogenes bacteria are rapidly processed and presented in the context of class I and class II major histocompatibility complex (MHC) antigens [13].

Despite the obvious importance of host-pathogen interactions in infected spleen during early infection for determining the outcome of systemic listeriosis, little is known about the fate of listeria in this organ during this phase of the infectious process. Other histological studies [14-16] have focused predominantly on events occurring after day 2 of infection and were inconclusive in revealing the location of the bacterial cells. Therefore, the present study was undertaken to examine the histopathogenesis of splenic infection during the first $48 \mathrm{~h}$. 


\section{Materials and methods}

Mice

CB6/F1 (C57BL/6 $\times$ BALB/c) adult male mice (9-10 weeks old) were obtained from the Trudeau Institute Animal Breeding Facility, Saranac Lake, NY, USA. They were free of common viral pathogens according to results of routine screening by the Research Animal Diagnostic Laboratory, University of Missouri, Columbia, MO, USA.

\section{Bacteria}

L. monocytogenes strain EGD was grown to mid-log phase at $37^{\circ} \mathrm{C}$ in a static culture of trypticase-soy broth, dispensed in $1-\mathrm{ml}$ volumes $\left(3 \times 10^{8} \mathrm{cfu} / \mathrm{ml}\right)$ and frozen at $-70^{\circ} \mathrm{C}$. For experimental use, frozen vials were thawed, the bacteria were washed once in sterile saline and diluted in saline for inoculation in a volume of $0.2 \mathrm{ml}$. Mice were inoculated with graded doses of bacteria in the range $10^{3}-10^{8} \mathrm{cfu}$. The i.v. LD50 of $L$. monocytogenes strain EGD for $\mathrm{CB} 6 / \mathrm{F} 1$ male mice is $c$. $5 \times 10^{3} \mathrm{cfu}$.

\section{Monoclonal antibody treatment}

The granulocyte-specific monoclonal antibody (MAb), RB6-8C5 [17], was given to mice to deplete them of neutrophils and thereby prevent the accumulation of these leucocytes at infectious foci. The hybridoma secreting MAb RB6-8C5 was a kind gift from R. Coffman (DNAX Research Institute, Palo Alto, CA, USA). MAb was purified from ascites as described previously [9] and was inoculated intraperitoneally into mice at a dose of $0.25 \mathrm{mg}$ in $0.2 \mathrm{ml}$ saline at 2 days, and again at $4 \mathrm{~h}$, before initiation of infection.

\section{Histology}

Mice were killed by cervical dislocation at various times during infection. Spleens were removed whole, placed in buffered formalin $10 \%$ solution, cut into small whole transverse pieces and fixed for $24 \mathrm{~h}$. The fixed tissue was then washed in water, dehydrated in ethanol and embedded in glycol methacrylate (JB-4 embedding kit; Polysciences Inc., Warrington, PA, USA). Thin (1$2 \mu \mathrm{m})$ sections were cut with glass knives, stained with MacNeal's tetrachrome and examined with a Nikon Microphot-Fx light microscope.

\section{Results}

\section{Histopathogenesis of murine listeriosis in the spleen}

To detect $L$. monocytogenes readily in thin sections, it was usually necessary to inoculate mice with large doses of bacteria that greatly exceeded the LD50 of the organism. This was especially the case during early infection before substantial bacterial multiplication occurred. However, regardless of inoculum size, mice always appeared healthy at the time they were killed. Moreover, where appropriate and feasible, the reported findings were confirmed with smaller inocula. Previous studies from this laboratory $[8,9]$ showed that neutrophil PMNLs that accumulate at foci of listeria infection in the liver engage and destroy infected hepatocytes, thereby causing extensive lesions in the parenchyma. Therefore, given that neutrophil PMNLs also predominate at foci of splenic infection during the first 2 days, the present study also examined whether these granulocytes are required to cause the observed histological changes in the spleen during this time.

Because others [3] have shown that $>99 \%$ of an i.v. inoculum of $L$. monocytogenes is removed from the blood by $1 \mathrm{~h}$ post-inoculation, mice were killed beginning $1 \mathrm{~h}$ after challenge in the present study. In control mice, by $1 \mathrm{~h}$ after i.v. inoculation of $10^{8} \mathrm{cfu}$, most listeria in the spleen were found in the marginal zone of the white pulp. Most bacteria in the marginal zone were associated with large round mononuclear cells with pale cytoplasm and nucleoplasm (Fig. 1), presumed to be [18] marginal zone macrophages (MZM). Bacteria were also associated with another mononuclear cell characterised by very densely staining cytoplasm and nucleoplasm and displaying prominent dendritic processes (Fig. 1), and referred to here as dendritic-like macrophages (DLM). Additionally, some bacteria were associated with neutrophils in marginal zone sinuses (not shown) and within mononuclear cells in the red pulp (Fig. 1). Despite the large inoculum size, no bacteria were found in the white pulp by $1 \mathrm{~h}$ of infection. The situation was similar in mice that received a 100 -fold lower inoculum, but at this dose bacteria were infrequently found (less than five bacteria per transverse section of spleen) within individual sections. At an inoculum of $10^{4} \mathrm{cfu}$ no bacteria were observed despite extensive searching. Many individual organisms in the present study were apparently surrounded by unstained haloes. These might repre- sent polymerised actin filaments that are known to nucleate around this pathogen after its invasion into host cell cytoplasm [10]. Alternatively, they might be artifacts of the embedding and staining procedures used.

By $6 \mathrm{~h}$ after inoculation of $10^{8}$ or $10^{6} \mathrm{cfu}$ of $L$. monocytogenes, neutrophil PMNL were accumulating at foci of infected monocytes in the marginal zone and red pulp (Fig. 2), and continued to accumulate at these sites during the following 2 days. Neutrophil PMNL failed to accumulate at infectious foci in mice treated with MAb RB6-8C5, thereby confirming the efficacy of this MAb treatment. By $6 \mathrm{~h}$, bacteria were still not obvious in the white pulp of control or neutrophildepleted mice. However, by $12 \mathrm{~h}$, listeria were found in the spleens of both groups of mice in the white pulp inside cells with the morphological characteristics of 


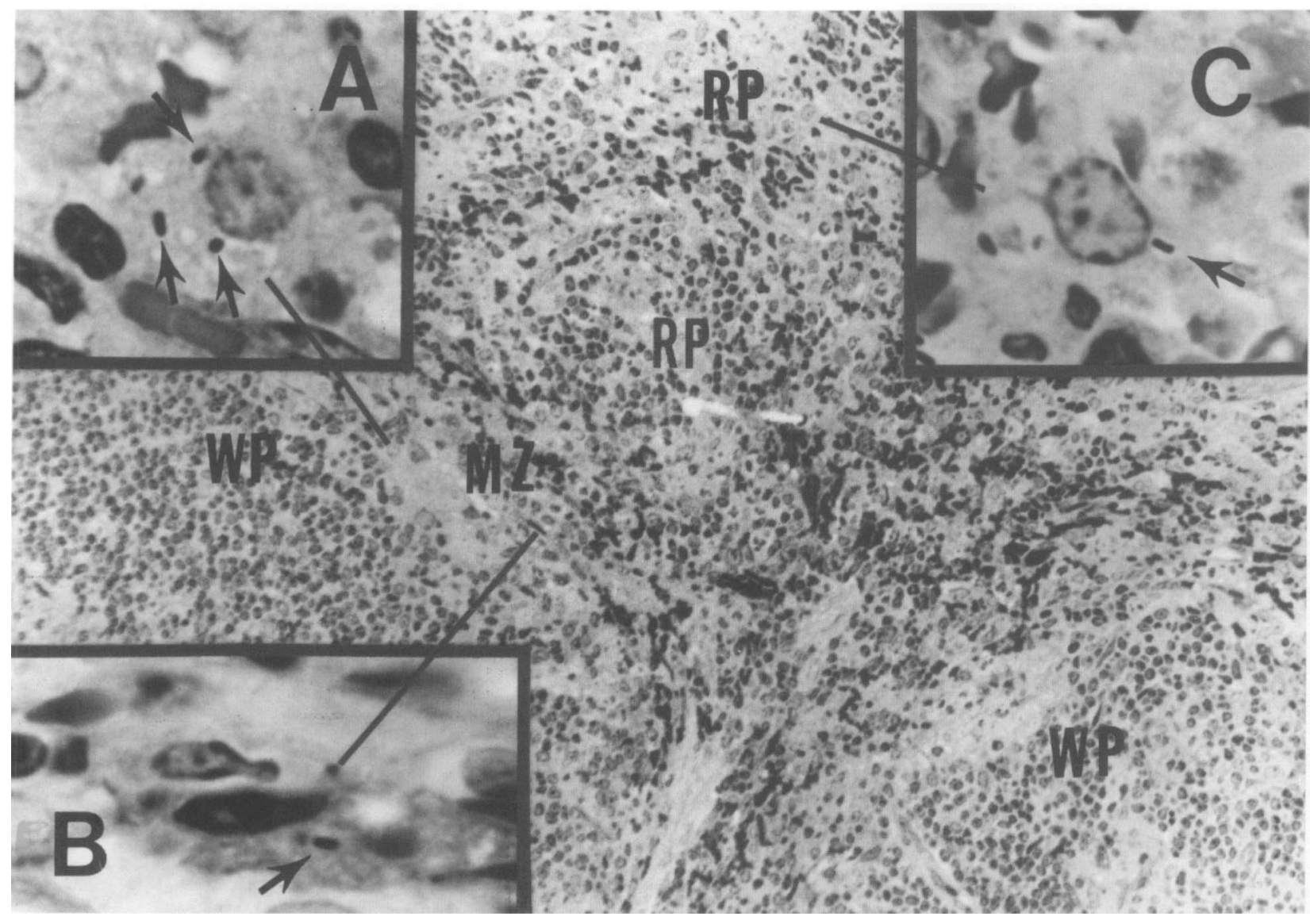

Fig. 1. Location of L. monocytogenes bacteria in the spleen $1 \mathrm{~h}$ after i.v. inoculation. Listeria (arrows) were found in the marginal zone (MZ) inside: A, large round mononuclear cells (presumed to be MZM) with lightly stained cytoplasm and nucleoplasm; B, dendritic mononuclear cells (DLM) with densely stained nucleoplasm and cytoplasm; C, additionally, by $1 \mathrm{~h}$, bacteria were found associated with mononuclear cells in the red pulp (RP). WP, white pulp. MacNeal's tetrachrome staining of plastic section. Magnification of main plate, $\times 290$; inset A, $\times 2330$; inset $B, \times 2330$; inset $\mathrm{C}, \times 1840$.

MZM or DLM (Fig. 3). In control mice, small accumulations of PMNLs were sometimes apparent in the white pulp in the vicinity of listeria-bearing monocytes by this time.

By $24 \mathrm{~h}$ after i.v. inoculation of $10^{6}$ or $10^{4} \mathrm{cfu}$ of L. monocytogenes, neutrophil PMNL accumulation at marginal zone infectious foci was extensive and extended into the white pulp and red pulp. Bacteria were present inside MZM and DLM in the white pulp, both within developing micro-abscesses as well as at sites devoid of obvious inflammatory cells (not shown). In mice treated with MAb RB6-8C5, neutrophil PMNLs were still essentially absent from infectious foci which, in the marginal zone, consisted of clumps of bacteria growing inside MZM and DLM (Fig. 4). Clumps of intracellular and extracellular bacteria were also found in the red pulp, albeit infrequently (not shown). Additionally, as in control mice, bacteria were observed inside MZM and DLM within the white pulp.

In control mice inoculated with $10^{4}$ or $10^{3}$ cfu of $L$. monocytogenes, in keeping with the findings of others $[15,16]$, some lymphoid follicles were mas- sively infiltrated by neutrophil PMNLs by $48 \mathrm{~h}$. These areas were essentially devoid of lymphocytes (Fig. 5), but the reticular framework of the white pulp appeared intact. Within white pulp lesions, bacteria were found inside PMNLs, DLM and MZM. In mice depleted of neutrophil PMNLs, as in control mice, lymphocytes were absent from the vicinity of infected, but not uninfected, white pulp (Fig. 6). In this situation listeria were present as large intracellular and extracellular clumps.

By day 4, in control mice inoculated with $10^{3}$ cfu of $L$. monocytogenes, PMNLs were far less prominent, and cellular inflammation was markedly reduced at infectious foci in the white pulp and red pulp of the spleen. Bacteria were found very infrequently within lesions by this time and, consequently, their association with particular host cells was not determinable. The paucity of bacteria at infectious foci on day 4 of sublethal infection presumably reflects the onset of bacterial sterilisation in the spleen by this time $[3,4,15,16]$. This being the case, no attempt was made to locate listeria in the spleen after day 4. All neutrophil PMNLdepleted mice inoculated with $\geqslant 10^{3}$ cfu of $L$. monocytogenes were dead by day 4 . 

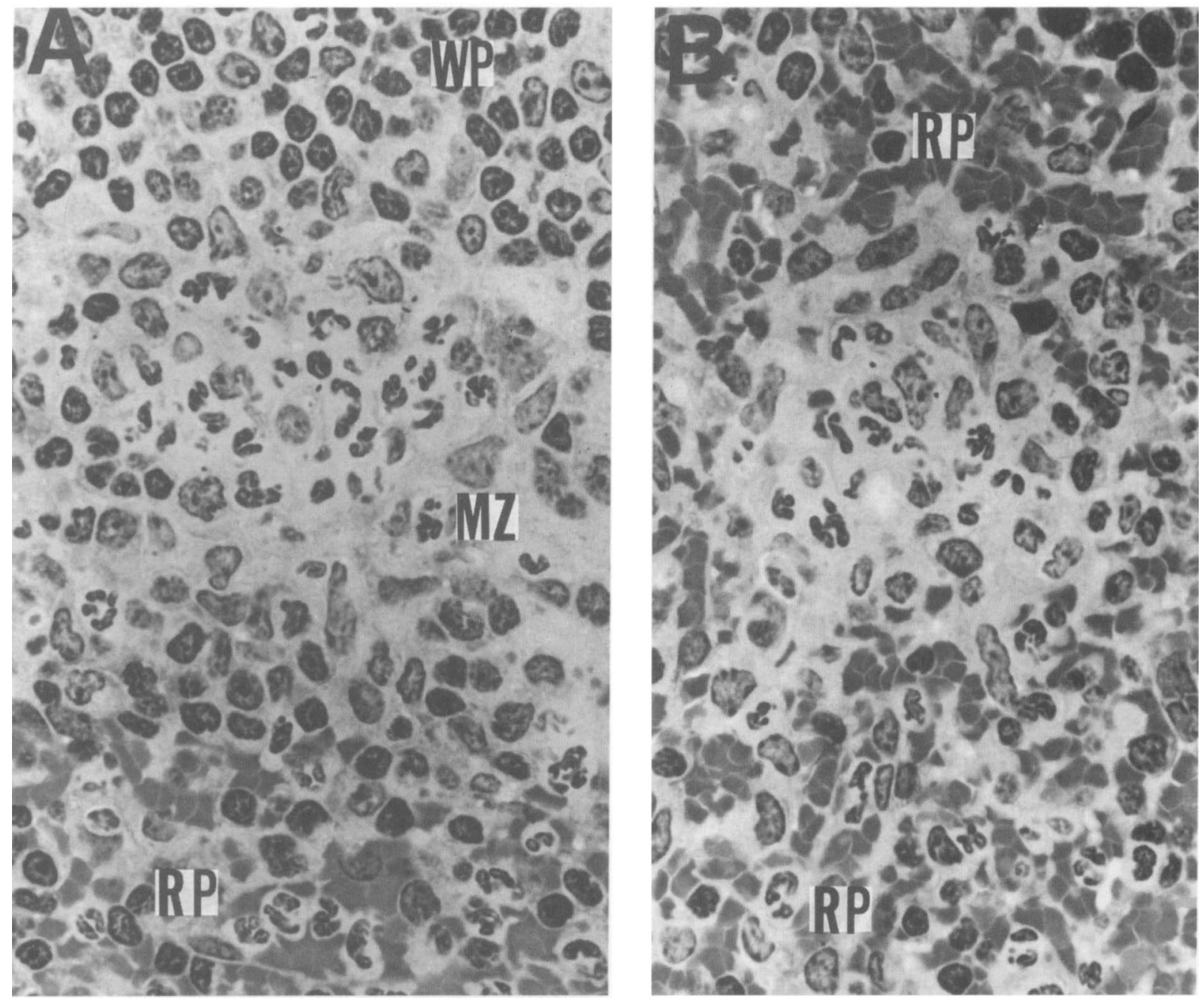

Fig. 2. Neutrophil PMNL accumulation at infectious foci. By $6 \mathrm{~h}$ after infection, neutrophil PMNLs were accumulating at foci of listeria infection in: A, the marginal zone; B, red pulp of the spleen. WP, white pulp; RP, red pulp; MZ, marginal zone. MacNeal's tetrachrome; plastic section. Magnification, $\times 875$.

\section{Discussion}

According to these results, intravenously inoculated $L$. monocytogenes bacteria that are taken up by the spleen are removed from the blood predominantly by mononuclear phagocytes in the marginal zone of the white pulp and the rest by mononuclear phagocytes in the red pulp. The same cells also ingested i.v. inocula of fluorescent and magnetic latex microparticles (not shown) and undoubtedly comprise the fixed phagocytes of the splenic reticulo-endothelial system $[12,18]$. This initial bacterial distribution presumably reflects the fact that most blood entering the spleen discharges first into marginal zone sinuses before entering the red pulp sinuses or splenic venules [18-20]. Therefore, bloodborne listeria are more likely to make contact with the fixed phagocytes lining the marginal zone sinuses before contacting other splenic macrophages.

Within the marginal zone, listeria were found associated with two morphologically distinct cell types. One, a large mononuclear cell with lightly staining cytoplasm and nucleoplasm, was morphologically reminiscent of marginal zone macrophages [18]. The other was a smaller cell with densely staining cytoplasm and nucleoplasm, and prominent dendritic processes. The latter cells are accordingly thought to be marginal metallophils [21] or dendritic cells [22], and morphologically appear akin to recently described 'barrier cells' [23], the functions of which are largely unknown. No bacteria were found in the white pulp during the first $6 \mathrm{~h}$ of infection, a finding in keeping with the fact that this compartment is extravascular. Therefore, listeria can only enter the white pulp by traversing the endothelial cells lining marginal sinuses $[12,19]$, which they appear to do inside the macrophages that initially ingested them. Additionally, because listeria can spread by direct intercellular transmission [10], it is possible that the organism also uses this mechanism to traverse into the white pulp from the marginal zone.

The translocation of listeria from the marginal zone into the white pulp is accompanied by an influx of neutrophil PMNLs into this compartment and by a disappearance of lymphocytes from the developing 


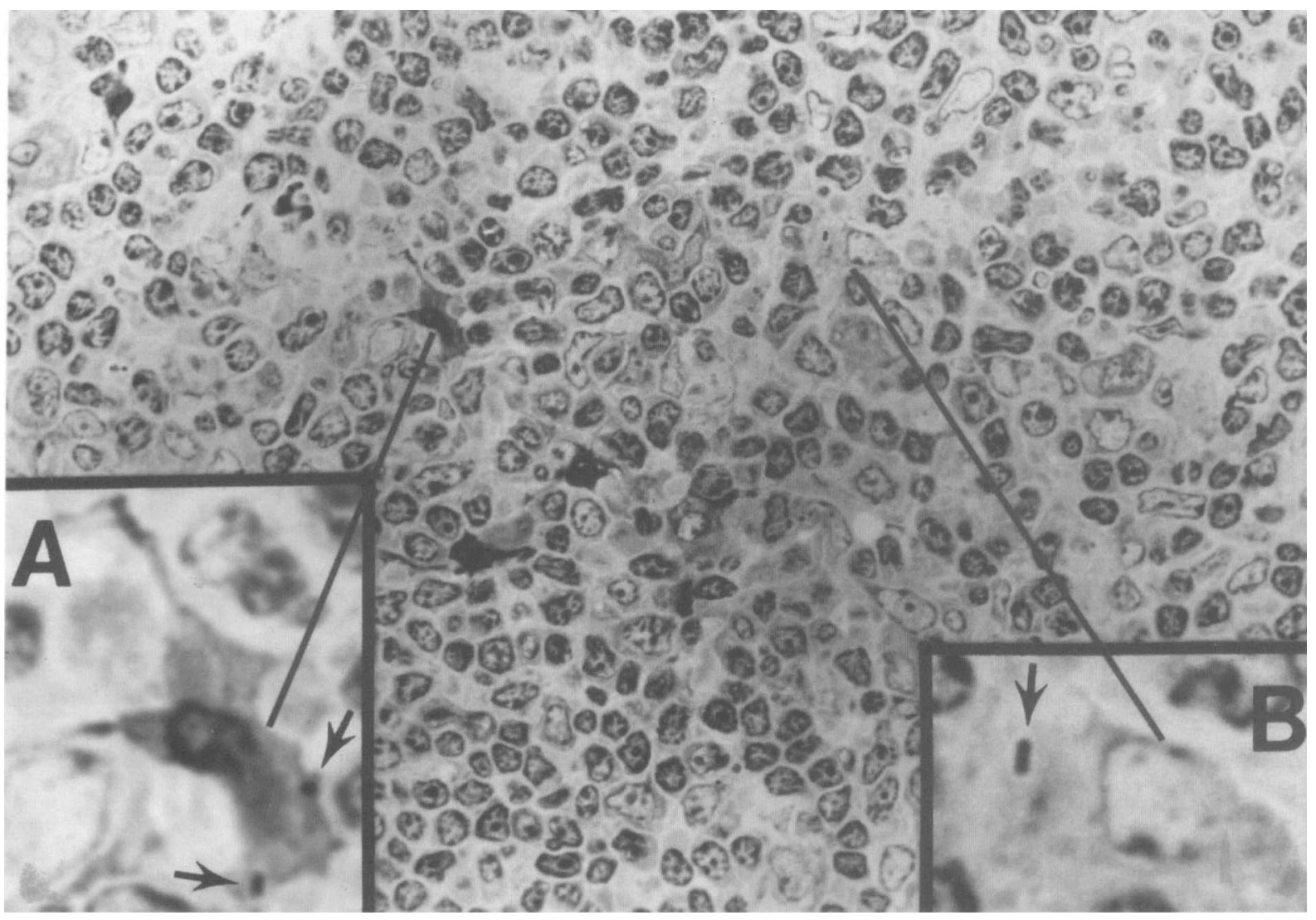

Fig. 3. Intracellular translocation of $L$. monocytogenes into the splenic white pulp. By $12 \mathrm{~h}$ after infection, listeria (arrows) were found withn the white pulp inside: $\mathbf{A}$, densely stained dendritic-like monocytes (DLM); B, lightly stained rounded monocytes reminiscent of MZM. Listeria-containing cells were in close physical proximity to lymphocytes. MacNeal's tetrachrome; plastic section. Magnification of main plate, $\times 865$; insets $\mathrm{A}$ and $\mathrm{B}, \times 2880$.

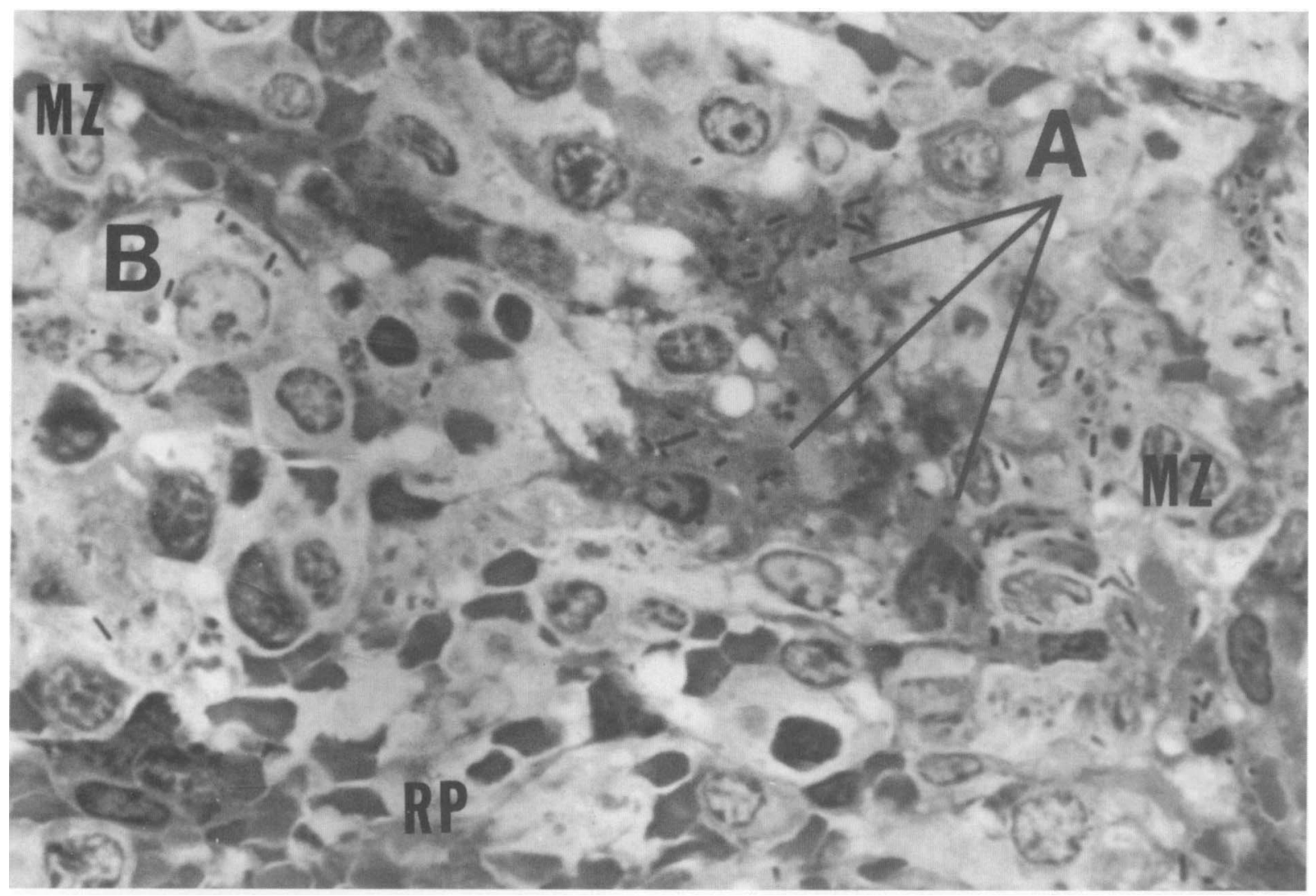

Fig. 4. Appearance of infectious foci in the spleens of neutropenic mice day by day 1 of infection. In the absence of neutrophil PMNLs in MAb RB6-8C5-treated mice, foci of infection in the marginal zone (MZ) consisted of clumps of bacteria inside; A, densely stained DLM; B, lightly stained MZM-like cells. RP, red pulp. MacNeal's tetrachrome staining of plastic section. Magnification, $\times 1550$. 


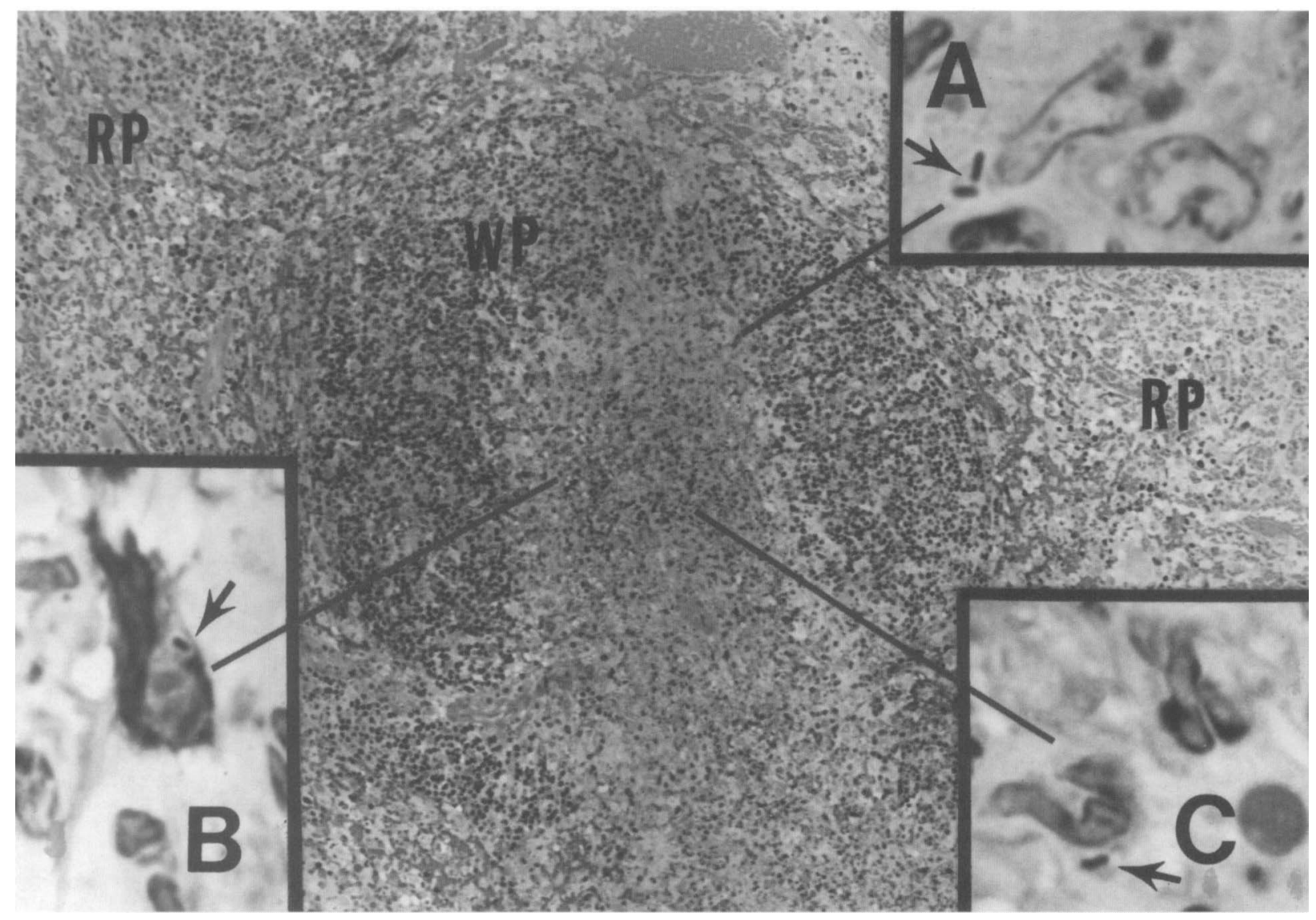

Fig. 5. Histological changes in the spleen by day 2 of infection. By this time, massive numbers of inflammatory cells, predominantly neutrophil PMNLs had infiltrated the white pulp (WP) in response to translocating listeria-infected cells. Within white pulp micro-abscesses, listeria (arrows) were found inside: $\mathbf{A}$, large rounded mononuclear cells; $\mathbf{B}$, densely stained dendritic cells; C, neutrophil PMNL. RP, red pulp. MacNeal's tetrachrome staining of plastic section. Magnification of main plate, $\times 290$; inset $A, \times 1260$; insets $B$ and $C, \times 1455$.

inflammatory focus. This aspect of splenic listeriosis has been described previously by others $[15,16]$, who suggested that lymphocytes might emigrate from infected white pulp. Alternatively, lymphocytes might be displaced to the peripheries of expanding inflammatory foci, or be destroyed therein by infiltrating neutrophils. However, the latter explanation seems unlikely given that lymphocytes are also depleted from infectious foci in the white pulp of neutrophil-depleted mice. Instead, the disappearance of lymphocytes from white pulp would appear to be a direct response to the infiltrating bacteria which are not considered to be cytotoxic. Nevertheless, as postulated by others $[15,16]$, the fact that white pulp lesions are not immediately repopulated by circulating lymphocytes suggests that lymphocyte homing into these particular areas might be impaired until infection begins to resolve.

Similar to the situation reported in the present study, inert particulate matter, including colloidal carbon, is transported into the white pulp within two distinct types of marginal zone macrophages [19]. Therefore, this might represent a common mechanism for delivering particulate antigens for presentation to lymphocytes resident in the white pulp. However, unlike viable, virulent $L$. monocytogenes bacteria, inert matter does not induce a massive inflammatory response. The extent to which the host cellular inflammatory response in the spleen is required for the production of listeria-specific $T$ cells is not known, but this organ is a major site for the generation of these $\mathrm{T}$ cells during the course of a primary infection $[3,4,6]$. Alternatively, the inflammatory response in this situation might contribute to the pathogenicity of $L$. monocytogenes, given that splenectomised mice reportedly are more resistant than control mice to primary infection with this pathogen [11].

However, the intracellular translocation of $L$. monocytogenes into the white pulp brings the organism and its antigens into proximity with lymphocytes capable of responding to them. For this reason it is important that the origin and identity of the listeria-bearing cells, and their antigen-presenting capacity be known. Certainly, antigen-presenting cells present listeria antigens in the context of both MHC class I and class II during primary infection $[2,5,13]$. However, whereas most cell types are capable of presenting antigen associated with class I MHC, only a few cell types, predominantly macrophages and dendritic cells, express MHC class II. In this regard, it is interesting to note that resident 

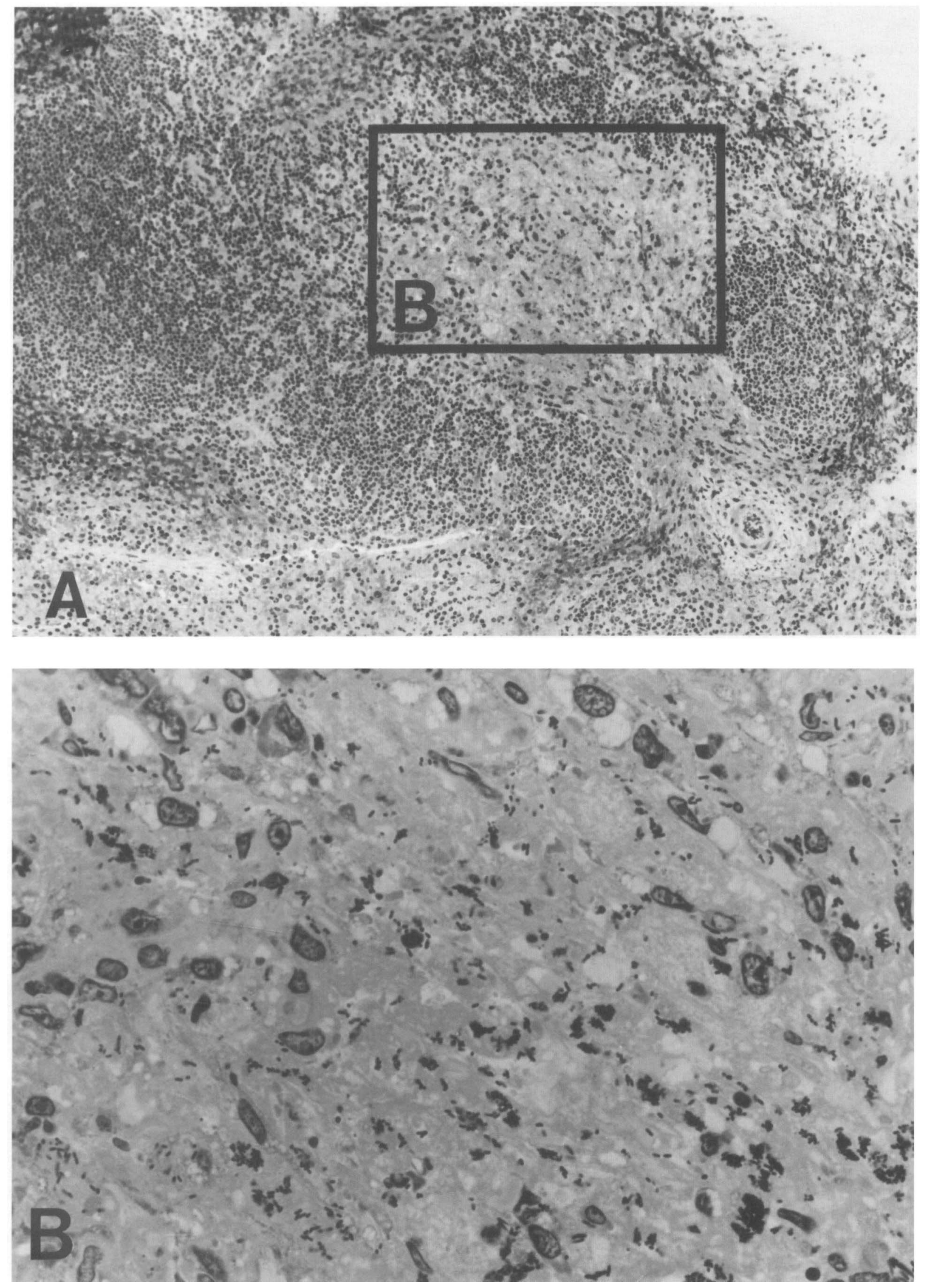

Fig. 6. Appearance of infectious foci in the spleens of neutrophil-depleted mice by day $2: \mathbf{A}$, by $48 \mathrm{~h}$ in these mice, lymphocytes have disappeared from infectious foci in the white pulp (boxed area B); B, boxed area in A at higher magnification showing listeria present as intracellular and extracellular clumps within infected white pulp. MacNeal's tetrachrome staining of plastic section. Magnification of $\mathrm{A}, \times 290 ; \mathrm{B}, \times 970$. 
splenic marginal zone macrophages reportedly express little, if any MHC class II antigen, even after stimulation [18]. By contrast, resident splenic dendritic cells express large quantities of MHC class II molecules on their surface and are extremely potent antigen-presenting cells [24]. Furthermore, immature dendritic cells can phagocytose particulate antigens including bacteria [25]. With these considerations in mind, experiments are in progress to phenotype the listeria-infected spleen cells described in the present study.

I thank Dr R. North for critically reading this manuscript, Louise Hartson for technical assistance, Lynn Ryan for photography, and Mary Durett and Sheila Kent for typing. This work was supported by a grant (IHP 42) from the Trudeau Institute.

\section{References}

1. Kaufmann SHE. Immunity to intracellular bacteria. Annu Rev Immunol 1993; 11: 129-163.

2. Czuprynski CJ, Brown JF. Dual regulation of anti-bacterial resistance and inflammatory neutrophil and macrophage accumulation by $\mathrm{L} 3 \mathrm{~T}^{+}$and $\mathrm{Lyt}^{+}$Listeria-immune $\mathrm{T}$ cells. Immunology 1987; 60: 287-293.

3. Mackaness GB. Cellular resistance to infection. $J$ Exp Med 1962; 116: 381-406.

4. Mackaness GB. The influence of immunologically committed lymphoid cells on macrophage activity in vivo. J Exp Med 1969; 129: 973-992.

5. Mielke MEA, Ehlers S, Hahn H. T-cell subsets in delayed-type hypersensitivity, protection, and granuloma formation in primary and secondary Listeria infection in mice: superior role of Lyt- $2^{+}$cells in acquired immunity. Infect Immun 1988; 56: $1920-1925$.

6. North RJ. Cellular kinetics associated with the development of acquired cellular resistance. $J$ Exp Med 1969; 130: 299-314.

7. North RJ. Cellular mediators of anti-Listeria immunity as an enlarged population of short-lived, replicating T cells. $J$ Exp Med 1973; 138: 342-355.

8. Conlan JW, North RJ. Roles of Listeria monocytogenes virulence factors in survival: virulence factors distinct from listeriolysin are needed for the organism to survive an early neutrophil-mediated host defense mechanism. Infect Immun 1992; 60: 951-957.

9. Conlan JW, North RJ. Neutrophils are essential for early anti-
Listeria defense in the liver, but not in the spleen or peritoneal cavity, as revealed by a granulocyte-depleting monoclonal antibody. J Exp Med 1994; 179: 259-268.

10. Portnoy DA, Chakraborty T, Goebel W, Cossart P. Molecular determinants of Listeria monocytogenes pathogenesis. Infect Immun 1992; 60: 1263-1267.

11. Skamene E, Chayasirisobhon W. Enhanced resistance to Listeria monocytogenes in splenectomized mice. Immunology 1977; 33: 851-858.

12. Van den Eertwegh AJM, Boersma WJA, Claassen E. Immunological functions and in vivo cell-cell interactions of $T$ cells in the spleen. Crit Rev Immunol 1992; 11: 337-380.

13. Pamer EG, Harty JT, Bevan MJ. Precise prediction of a dominant class I MHC-restricted epitope of Listeria monocytogenes. Nature 1991; 353: 852-855.

14. Armstrong BA, Sword CP. Electron microscopy of Listeria monocytogenes infected mouse spleen. J Bacteriol 1966; 91: 1346-1355.

15. Chan YY, Cheers C. Mechanism of depletion of $T$ lymphocytes from the spleen of mice infected with Listeria monocytogenes. Infect Immun 1982: 38: 686-693.

16. Mandel TE, Cheers C. Resistance and susceptibility of mice to bacterial infection: histopathology of listeriosis in resistant and susceptible strains. Infect Immun 1980; 30: 851-861.

17. Tepper RI, Coffman RL, Leder P. An eosinophil-dependent mechanism for the anti-tumor effect of interleukin-4. Science 1992; 257: 548-551

18. Humphrey JH, Grennan D. Different macrophage populations distinguished by means of fluorescent polysaccharides. Recognition and properties of marginal-zone macrophages. Eur $J$ Immunol 1981; 11: 221-228.

19. Kotani M, Matsuno K, Miyakawa K, Ezaki T, Hayama T, Ekino S. Migration of macrophages from the marginal zone to germinal centers in the spleen of mice. Anat Rec 1985; 212: 172-178.

20. Weiss L. The spleen. In: Weiss L (ed) Cell and tissue biology. A textbook of histology, 6th edn. Baltimore, Urban and Schwartzenberg. 1988.

21. Snook T. Studies on the perifollicular region of the rat's spleen. Anat Rec 1964; 148: 149-159.

22. Steinman RM, Adams JC, Cohn ZA. Identification of a novel cell type in peripheral lymphoid organs of mice. IV. Identification and distribution in mouse spleen. $J$ Exp Med 1975; 141: 804-820.

23. Weiss L. Barrier cells in the spleen. Immunol Today 1991; 12: 24-29.

24. Crowley $M$, Inaba $K$, Steinman RM. Dendritic cells are the principal cells in mouse spleen bearing immunogenic fragments of foreign proteins. $J$ Exp Med 1990: 172: 383-386.

25. Inaba $\mathrm{K}$, Inaba $\mathrm{M}$, Naito $\mathrm{M}$, Steinman $\mathrm{RM}$. Dendritic cell progenitors phagocytose particulates, including bacillus Calmette-Guerin organisms, and sensitize mice to mycobacterial antigens in vivo. $J$ Exp Med 1993; 178: 479-488. 